\title{
Clinical Effect of Evjiv Combined with Oral Lipoic Acid on Patients with Diabetic Foot
}

\author{
YING ZHOU*, MING ZHEN LI ${ }^{1}$ AND ZHEN HUAN JIANG ${ }^{2}$
}

Department of Diabetic Foot, ${ }^{1}$ Depatment of Gout, ${ }^{2}$ Depatment of Metabolic Disease, NHC Key Laboratory of Hormones and Development, Tianjin Key Laboratory of Metabolic Diseases, Chu Hsien-I Memorial Hospital \& Tianjin Institute of Endocrinology, Tianjin Medical University, No.6 North Huanrui Rd, Beichen District, Tianjin 300134, P. R. China

\section{Zhou et al.: Clinical Effect of Evjiv Combined with Oral Lipoic Acid}

\begin{abstract}
To investigate the clinical effect of the combination of evjiv and oral lipoic acid in the treatment of diabetic foot and its effect of oxidative stress and inflammation is the objective. 100 patients with diabetic foot treated in our hospital from January 2020 to March 2021 were selected and random divided into control group and observation group. Patients in control group were treated with basic treatment regimen and patients in observation group were treated with evjiv combined with oral lipoic acid on the basis of the control group. The treatment effects, oxidative stress indexes and inflammation indexes of the patients in the two groups were compared after treatment. After treatment, the total effective rate of patients in observation group was significantly higher than that in control group. Fasting blood glucose and $2 \mathrm{~h}$ postprandial blood glucose of patients in both groups were lower than those before treatment. Serum advanced oxidation protein products and malondialdehyde in observation group were lower than those in control group and superoxide dismutase was higher than that in control group. The vascular cell adhesion molecule-1, fibroblast growth factor 2, tumor necrosis factor alpha and interleukin-6 in both groups were lower than those before treatment. The positive rate of bacterial culture on the sore surface in observation group was significantly lower than that in control group and these difference were statistically significant $(p<0.05)$. The use of lipoic acid combined with evjiv in the early stage of diabetic foot can effectively improve the oxidative stress and inflammation of patients and improve the clinical efficacy.
\end{abstract}

Key words: Diabetic foot, evjiv, oral lipoic acid, oxidative stress, inflammatory response

Diabetes, as the third common chronic noncommunicable disease affecting human health, has become an increasingly serious public health problem. Diabetic peripheral neuropathy is one of the most common complications of diabetes and foot is a complex target organ of diabetes, a multi system disease $^{[1]}$. Diabetic patients with peripheral neuropathy and peripheral vascular disease combined with high mechanical pressure can cause foot soft tissue and bone joint system damage and deformity and then lead to a series of mild neurological symptoms to severe ulcer, infection, vascular disease, Charcot joint disease and neurodegenerative fracture ${ }^{[2,3]}$. If the treatment cannot fully solve the symptoms and complications of lower limbs, it will not only seriously affect the health and quality of life of patients but also cause great economic burden for patients themselves and society. The purpose of this study was to investigate the clinical efficacy of the combination of evjiv and lipoic acid in the treatment of diabetic foot and its effect on oxidative stress response and inflammatory indexes.

\section{MATERIALS AND METHODS}

\section{General clinical data:}

A total of 100 patients with diabetic foot treated in our hospital from January 2020 to March 2021 were selected and randomly divided into control group and observation group, 50 cases in each group. The observation group included 37 males and 13 females, aged 40-72 y, with an average age of (53.24 \pm 3.06$) \mathrm{y}$ and an average course of diabetes of $(9.1 \pm 2.2) \mathrm{y}$; the control group included 36 males and 14 females, with an average age of $(52.93 \pm 2.78) \mathrm{y}$ and an average course of diabetes of (8.9 \pm 1.9$)$ y. After analyzing and comparing the basic data and the average course of diabetes between the two groups, there was no significant difference $(\mathrm{p}>0.05)$.

*Address for correspondence

E-mail: cj19830321@163.com 
Inclusive criteria; Clinical symptoms met the diagnostic criteria of diabetic foot ${ }^{[4]}$; Wagner grade was $1-2^{[5]}$.

Exclusion criteria includes Type 1 diabetes mellitus; patients with allergic symptoms to the drugs used in this study; patients with severe diseases of other important organs; patients who could not observe the medication time. All patients agreed and signed the informed consent.

\section{Methods:}

The control group was treated with basic treatment. Insulin or oral hypoglycemic drugs were used to control blood glucose between 6 and $8 \mathrm{mmol} / 1$, antibiotics were used to treat infection, sensitive antibiotics were selected according to bacterial culture, water electrolyte balance was maintained, microcirculation was improved and other complications of diabetes were actively treated. Local debridement: use $0.9 \%$ sodium chloride injection to wash the wound surface, remove necrotic tissue and expose fresh granulation tissue. After debridement and dressing change, the wound surface was rinsed with hydrogen peroxide solution, wiped with Iodophor $(0.02$ $\%)$ and dried with sterile gauze. The surface of the wound surface was covered with sterile Vaseline gauze and then covered with sterile gauze.

The patients in the observation group were treated with evjiv combined with oral lipoic acid on the basis of the control group. The patient took $100 \mathrm{mg}$ of $\alpha$-lipoic acid orally twice a day, while debridement and dressing change were first disinfected by wiping with Iodophor, then local spraying of evjiv (external application of lyophilized recombinant human acidic fibroblast growth factor) solution and then covered or stuffed with sterile Vaseline gauze on the surface of the wound and then covered with sterile gauze. Both groups were treated for $2 \mathrm{mo}$. The frequency of dressing change in the two groups depends on the exudation of the wound, generally 1-2 d.

\section{Observation index:}

At the end of the treatment course, the therapeutic effect of the two groups was observed. Fasting blood glucose, 2 h postprandial blood glucose, glycosylated hemoglobin, advanced oxidation protein products (AOPPs), superoxide dismutase (SOD), malondialdehyde (MDA), vascular cell adhesion molecule-1 (VCAM1), fibroblast growth factor 2 (FGF2), interleukin-6 (IL-6) and tumor necrosis factor alpha (TNF- $\alpha$ ) were detected before and after treatment. Fasting blood glucose and $2 \mathrm{~h}$ postprandial blood glucose were detected by glucose oxidase, glycosylated hemoglobin by ion exchange chromatography, SOD and MDA by thiobarbituric acid reaction, AOPPs, VCAM, FGF2 and TNF- $\alpha$ by enzyme immunoadsorption and IL- 6 by electrochemiluminescence. The change of the positive rate of bacterial culture on ulcer surface was observed before and after treatment. Collection and identification of bacteria on the wound surface before the change of first dressing and 1 mo after the change of dressing was carried out and wet cotton swabs were used to take the secretion from the wound surface for examination.

\section{Efficacy criteria:}

Markedly effective-the patient's lower limbs have no pain and numbness and the symptoms of lower limbs cooling have completely disappeared and the patient's wound area is more than $80 \%$; effective: the patient's lower limb pain and numbness have been relieved and the wound healing area is $40 \%-80 \%$; ineffective: the patient's condition has no obvious improvement or although there is improvement, the wound healing area is less than $40 \%{ }^{[6]}$. Total effective rate $=$ (markedly effective cases + effective cases)/total cases $\times 100 \%$.

\section{Statistical analysis:}

All data were analyzed by SPSS 16.0 software. The measurement data were expressed as $(\mathrm{x} \pm \mathrm{s})$. Paired t-test was used for comparison between groups, $\mathrm{p}<0.05$ was considered statistically significant.

\section{RESULTS AND DISCUSSION}

Comparison of clinical efficacy between the two groups was observed. After treatment, the total effective rate of the observation group was significantly higher than that of the control group $(p<0.05)$ and the clinical efficacy of the observation group was better than that of the control group ( $\mathrm{p}<0.05)$, as shown in Table 1 .

Comparison of the changes of blood glucose and glycosylated hemoglobin between the two groups before and after treatment was observed. There was no significant difference in fasting blood glucose, $2 \mathrm{~h}$ postprandial blood glucose and glycosylated hemoglobin between the two groups before and after treatment $(\mathrm{p}>0.05)$. After treatment, fasting blood glucose and $2 \mathrm{~h}$ postprandial blood glucose of the two groups were lower than before treatment $(p<0.05)$; there was no significant difference in glycosylated hemoglobin between the two groups $(p>0.05)$, as shown in Table 2. 
TABLE 1: COMPARISON OF CLINICAL EFFICACY BETWEEN THE TWO GROUPS

\begin{tabular}{lccccc}
\hline Groups & N & Markedly effective & Effective & Ineffective & Total effective rate (\%) \\
\hline Observation group & 50 & 27 & 16 & 7 & $43(86.00)$ \\
Control group & 50 & 15 & 18 & 17 & $33(66.00)$ \\
\hline
\end{tabular}

TABLE 2: COMPARISON OF THE CHANGES OF BLOOD GLUCOSE AND GLYCOSYLATED HEMOGLOBIN BETWEEN THE TWO GROUPS BEFORE AND AFTER TREATMENT

\begin{tabular}{lcccc}
\hline \multirow{2}{*}{ Projects } & \multicolumn{2}{c}{ Control group $(\mathrm{N}=50)$} & \multicolumn{2}{c}{ Observation group $(\mathrm{N}=50)$} \\
\cline { 2 - 5 } & Before treatment & After treatment & Before treatment & After treatment \\
\hline Fasting blood glucose $(\mathrm{mmol} / \mathrm{l})$ & $8.4 \pm 2.1$ & $7.2 \pm 1.6^{\#}$ & $8.5 \pm 2.0$ & $7.1 \pm 1.8^{\#}$ \\
$2 \mathrm{~h}$ postprandial blood glucose & $13.3 \pm 3.3$ & $9.2 \pm 3.1^{\#}$ & $13.5 \pm 3.4$ & $9.4 \pm 3.3^{\#}$ \\
(mmol/l) & $8.9 \pm 2.1$ & $8.3 \pm 1.8$ & $9.0 \pm 2.3$ & $8.4 \pm 2.6$ \\
\hline
\end{tabular}

Note: Compared with the before treatment, ${ }^{\#} \mathrm{p}<0.05$

Comparison of oxidative stress indexes before and after treatment between the two groups was measured. Before treatment, there was no significant difference in AOPPs, SOD and MDA between the two groups $(\mathrm{p}>0.05)$. After treatment, the AOPPs and MDA values of the two groups were lower than before treatment and the observation group was lower than the control group $(p<0.05)$. In addition, SOD value was higher than before treatment and the observation group was higher than the control group, the difference was statistically significant $(\mathrm{p}<0.05)$, as shown in Table 3.

Comparison of inflammatory indexes between the two groups before and after treatment was observed. Before treatment, there were no significant differences in VCAM-1, FGF2, TNF- $\alpha$ and IL-6 between the two groups $(p>0.05)$. After treatment, VCAM, FGF2, TNF- $\alpha$, IL- 6 of the two groups were lower than before treatment and the observation group was lower than the control group $(\mathrm{p}<0.05)$, as shown in Table 4 .

Comparison of positive rate of bacterial culture on sore surface between two groups before and after treatment was observed. Before treatment, there was no significant difference in the positive rate of ulcer surface bacterial culture between the two groups $(\mathrm{p}>0.05)$; after treatment, the positive rate of ulcer surface bacterial culture in the observation group was significantly lower than that in the control group $(\mathrm{p}<0.05)$, as shown in Table 5 .

TABLE 3: COMPARISON OF OXIDATIVE STRESS INDEXES BEFORE AND AFTER TREATMENT BETWEEN THE TWO GROUPS

\begin{tabular}{lcccc}
\hline \multirow{2}{*}{ Projects } & \multicolumn{2}{c}{ Control group $(\mathrm{N}=50)$} & \multicolumn{2}{c}{ Observation group $(\mathrm{N}=50)$} \\
\cline { 2 - 5 } & Before treatment & After treatment & Before treatment & After treatment \\
\hline AOPP $(\mathrm{mmol} / \mathrm{l})$ & $65 \pm 10$ & $58 \pm 9^{\#}$ & $65 \pm 10$ & $53 \pm 7^{\# *}$ \\
SOD $(\mathrm{U} / \mathrm{l})$ & $27 \pm 5$ & $30 \pm 6^{\#}$ & $26 \pm 5$ & $33 \pm 6^{\# *}$ \\
MDA $(\mathrm{mmol} / \mathrm{l})$ & $6.8 \pm 0.9$ & $5.7 \pm 0.7^{\#}$ & $6.8 \pm 0.9$ & $4.7 \pm 0.5^{\# *}$ \\
\hline
\end{tabular}

Note: Compared with the pre-treatment, ${ }^{*} \mathrm{p}<0.05$; Compared with the control group, ${ }^{*} \mathrm{p}<0.05$

TABLE 4: COMPARISON OF INFLAMMATORY INDEXES BETWEEN THE TWO GROUPS BEFORE AND AFTER TREATMENT

\begin{tabular}{lcccc}
\hline \multirow{2}{*}{ Projects } & \multicolumn{2}{c}{ Control group $(\mathrm{N}=50)$} & \multicolumn{2}{c}{ Observation group (N=50) } \\
\cline { 2 - 5 } & Before treatment & After treatment & Before treatment & After treatment \\
\hline VCAM-1 $(\mathrm{g} / \mathrm{l})$ & $1136 \pm 300$ & $1004 \pm 266^{\#}$ & $1127 \pm 305$ & $810 \pm 205^{\# *}$ \\
FGF2 $(\mathrm{ng} / \mathrm{l})$ & $16.0 \pm 4.2$ & $12.4 \pm 2.7^{\#}$ & $16.0 \pm 4.3$ & $9.1 \pm 2.6^{\# *}$ \\
TNF-a $(\mathrm{pg} / \mathrm{l})$ & $22 \pm 6$ & $18 \pm 5^{\#}$ & $22 \pm 6$ & $14 \pm 4^{\# *}$ \\
$\mathrm{IL}-6(\mathrm{pg} / \mathrm{l})$ & $23 \pm 6$ & $18 \pm 5^{\#}$ & $23 \pm 6$ & $13 \pm 4^{\# *}$ \\
\hline
\end{tabular}

Note: Compared with the pre-treatment, ${ }^{*} \mathrm{p}<0.05$; Compared with the control group, ${ }^{*} \mathrm{p}<0.05$ 
TABLE 5: COMPARISON OF POSITIVE RATE OF BACTERIAL CULTURE ON SORE SURFACE BETWEEN TWO GROUPS BEFORE AND AFTER TREATMENT

\begin{tabular}{lccc}
\hline Groups & N & Before treatment & After treatment \\
\hline Observation group & 50 & $46(92.00)$ & $12(24.00)^{\# *}$ \\
Control group & 50 & $47(94.00)$ & $23(46.00)^{\#}$ \\
\hline
\end{tabular}

Note: Compared with the pre-treatment, ${ }^{\#} \mathrm{p}<0.05$; Compared with the control group, ${ }^{*} \mathrm{p}<0.05$

Diabetic foot is the most common, serious and costly complication of diabetes ${ }^{[6]}$, which is caused by the destruction or deformity of soft tissue and bone joint system caused by excessive mechanical pressure on the foot $^{\left[{ }^{[7]}\right.}$. If the early diabetic foot is not treated in time, it may cause some serious symptoms and complications in the lower limbs of patients ${ }^{[8]}$. In patients with diabetic foot, long-term disease will make their sensory nerve, motor nerve lesions, coupled with high mechanical pressure, eventually lead to foot ulceration and infection $^{[9]}$. The patient's foot will lose consciousness and under a certain degree of repeated external force, the foot will cause inflammation and tissue damage, such as the pressure from the ground or shoes. Due to the lack of normal neuroprotective mechanism, the ulcer of patients is often aggravated by the presence of bone process. The pathological changes of autonomic nervous system result in the loss of normal skin function of perspiration regulation, skin temperature regulation and blood circulation regulation, which leads to the decrease of local tissue flexibility, the formation of thick corpus callosum and more easily broken and cracked. In addition, the loss of normal perspiration blocked the rehydration of local tissues, resulting in further tissue destruction and making deep tissues easier for bacterial colonization.

Oxidative stress refers to the imbalance between oxidation and anti-oxidation in human body and tends to be oxidative, which makes neutrophil inflammatory infiltration, increases protease secretion and produces a large number of oxidation intermediates ${ }^{[10]}$. Oxidative stress can damage insulin antibody and islet $\beta$ cells. Therefore, the pathogenesis of diabetes is based on oxidative stress ${ }^{[11]}$. Inflammation is a kind of defensive pathological reaction when the body is under adverse stimulation ${ }^{[12]}$. In the process of inflammation development, damage factors will damage cells and at the same time, they will surround the damage factors through inflammatory reaction. After pathogens invade the body, the body is in a state of stress. Oxidative stress causes hypercoagulable state, leading to tissue ischemia, activation of complement system, or production of a variety of chemotactic substances. Therefore, in the process of inflammatory reaction, oxidative stress can be increased, the antioxidant capacity of cells will be reduced, the production of free radicals will be increased and the structure and function of protein will be damaged, leading to deoxyribonucleic acid (DNA) mutation.

Lipoic acid is a vitamin like coenzyme, which mainly exists in mitochondria and can effectively eliminate free radicals. It is a multifunctional antioxidant. Studies have found that lipoic acid can correct oxidative stress induced by hyperglycemia through a variety of mechanisms ${ }^{[13]}$. Lipoic acid can preserve and regenerate other antioxidants, balance the concentration of blood glucose and effectively enhance the body's immune system $^{[14]}$. It has been reported that lipoic acid has a significant effect on the early stage of diabetic foot ${ }^{[15]}$. Evjiv is a recombinant human acidic fibroblast growth factor, which has a wide range of biological effects. Its main mechanism of promoting wound healing is to promote the formation of capillaries and epithelium, promote the growth of granulation tissue and shorten the healing time. It can also inhibit the excessive formation of collagen in the process of wound repair, so as to prevent the excessive formation of $\operatorname{scar}^{[16]}$.

The results showed that the total effective rate of the observation group was significantly higher than that of the control group $(p<0.05)$. The biochemical reaction of lipoic acid is in mitochondria, which is the energy center of cells. Lipoic acid is a necessary factor in the glucose energy metabolism cycle of human body. Although human body can synthesize lipoic acid for basic physiological reaction, the additional supplement of lipoic acid can significantly improve the sensitivity of diabetic cells to insulin. The results of this study also showed that after treatment, fasting blood glucose of the two groups could be reduced, $2 \mathrm{~h}$ postprandial blood glucose was lower than before treatment; AOPPs and MDA of the observation group were lower than those of the control group, SOD was higher than that of the control group $(p<0.05)$; the levels of VCAM, FGF2, TNF- $\alpha$ and IL- 6 in the observation group were lower than those in the control group $(p<0.05)$, indicating that lipoic acid combined with evjiv can effectively treat early diabetic foot and improve oxidative stress and 
inflammation.

In conclusion, in the early stage of diabetic foot, the use of lipoic acid combined with evjiv can effectively improve the oxidative stress and inflammation of patients and improve the clinical efficacy.

\section{Acknowledgements:}

This work was supported by the NHC Key Laboratory of Hormones and Development, Tianjin Key Laboratory of Metabolic Diseases, Chu Hsien-I Memorial Hospital \& Tianjin Institute of Endocrinology, Tianjin Medical University.

\section{Conflicts of interest:}

The authors declared no conflict of interest.

\section{REFERENCES}

1. Magrinelli F, Fabrizi GM, Santoro L, Manganelli F, Zanette G, Cavallaro T, et al. Pharmacological treatment for familial amyloid polyneuropathy. Cochrane Database Syst Rev 2020;4(4):CD012395.

2. Boulton AJ, Malik RA, Arezzo JC, Sosenko JM. Diabetic somatic neuropathies. Diabetes care 2004;27(6):1458-86.

3. Boulton AJ, Vinik AI, Arezzo JC, Bril V, Feldman EL, Freeman $\mathrm{R}$, et al. Diabetic neuropathies: a statement by the American Diabetes Association. Diabetes care 2005;28(4):956-62.

4. Coppini DV, Bowtell PA, Weng C, Young PJ, Sonksen PH. Showing neuropathy is related to increased mortality in diabetic patients-a survival analysis using an accelerated failure time model. J Clin Epidemiol 2000;53(5):519-23.

5. Daousi C, MacFarlane IA, WoodwardA, Nurmikko TJ, Bundred PE, Benbow SJ. Chronic painful peripheral neuropathy in an urban community: a controlled comparison of people with and without diabetes. Diabet Med 2004;21(9):976-82.

6. Degu H, Wondimagegnehu A, Yifru YM, Belachew A. Is health related quality of life influenced by diabetic neuropathic pain among type II diabetes mellitus patients in Ethiopia? PLoS One 2019;14(2):e0211449.
7. Montero AA, Ibor Vidal PJ, Verdugo AA, Calvo ET. Update in the pharmacological treatment of neuropathic pain. Semergen 2019;45(8):535-45.

8. Cameron NE, Eaton SE, Cotter MA, Tesfaye S. Vascular factors and metabolic interactions in the pathogenesis of diabetic neuropathy. Diabetologia 2001;44(11):1973-88.

9. Ziegler D. Thioctic acid for patients with symptomatic diabetic polyneuropathy. Treat endocrinol 2004;3(3):173-89.

10. Bril V, Buchanan RA. Long-term effects of ranirestat (AS3201) on peripheral nerve function in patients with diabetic sensorimotor polyneuropathy. Diabetes care 2006;29(1):68-72.

11. Papanas N, Ziegler D. Efficacy of $\alpha$-lipoic acid in diabetic neuropathy. Expert Opin Pharmacother 2014;15(18):2721-31.

12. Ziegler D, Sohr CG, Nourooz-Zadeh J. Oxidative stress and antioxidant defense in relation to the severity of diabetic polyneuropathy and cardiovascular autonomic neuropathy. Diabetes care 2004;27(9):2178-83.

13. Ziegler D, Nowak H, Kempler P, Vargha P, Low PA. Treatment of symptomatic diabetic polyneuropathy with the antioxidant $\alpha$-lipoic acid: a meta-analysis. Diabetic Med 2004;21(2):11421.

14. Ziegler D, Ametov A, Barinov A, Dyck PJ, Gurieva I, Low PA, et al. Oral treatment with $\alpha$-lipoic acid improves symptomatic diabetic polyneuropathy: the Sydney 2 trial. Diabetes care 2006;29(11):2365-70.

15. Ruhnau KJ, Meissner HP, Finn JR, Reljanovic M, Lobisch $\mathrm{M}$, Schutte K, et al. Effects of 3-week oral treatment with the antioxidant thioctic acid ( $\alpha$-lipoic acid) in symptomatic diabetic polyneuropathy. Diabetic Med 1999;16(12):1040-3.

16. Coppey LJ, Gellett JS, Davidson EP, Dunlap JA, Lund DD, Yorek MA. Effect of antioxidant treatment of streptozotocininduced diabetic rats on endoneurial blood flow, motor nerve conduction velocity, and vascular reactivity of epineurial arterioles of the sciatic nerve. Diabetes 2001;50(8):1927-37.

This is an open access article distributed under the terms of the Creative Commons Attribution-NonCommercial-ShareAlike 3.0 License, which allows others to remix, tweak, and build upon the work non-commercially, as long as the author is credited and the new creations are licensed under the identical terms

This article was originally published in a special issue,
"Therapeutic Perspectives in Biomedical Research and Pharma-
ceutical Sciences and their Nursing Methods"
Indian J Pharm Sci 2021:83(4)Spl issue "45-49"

